\title{
Mini-Symposium
}

\section{Chemokine Action in the Nervous System}

\author{
Richard J. Miller, ${ }^{1}$ William Rostene, ${ }^{2}$ Emanuelle Apartis, ${ }^{2,3}$ Ghazal Banisadr, ${ }^{1}$ Knut Biber, ${ }^{4}$ Erin D. Milligan, ${ }^{5}$ \\ Fletcher A. White, ${ }^{6}$ and Ji Zhang ${ }^{7}$ \\ ${ }^{1}$ Department of Molecular Pharmacology and Biological Chemistry, Northwestern University Medical School, Chicago, Illinois 60611, ${ }^{2}$ Inserm, Unité Mixte \\ 732, Université Pierre et Marie Curie Paris 06, Hôpital Saint-Antoine, 75016 Paris, France, ${ }^{3}$ Department of Neurology, Saint-Antoine Hospital, Assistance \\ Publique des Hôpitaux de Paris, 75012 Paris, France, ${ }^{4}$ Department of Neurosciences, Medical Physiology Section, University Medical Center Groningen, \\ University of Groningen, 9713 AV Groningen, The Netherlands, ${ }^{5}$ Department of Neurosciences, University of New Mexico, Health Sciences Center, \\ Albuquerque, New Mexico 87131-0001, 'Department of Cell Biology Neurobiology, and Anatomy and Anesthesiology, Loyola University Chicago, \\ Maywood, Illinois 60626, and ${ }^{7}$ The Alan Edwards Center for Research on Pain, McGill University, Montreal, Quebec, Canada H3A 2B2
}

Key words: cytokine; neuron; microglia; inflammation; neuropathic pain; neurogenesis

Inflammatory cytokines are a family of molecules that coordinate inflammatory and immune responses. One important class of inflammatory cytokines are the chemokines (for CHEMOtactic cytoKINES). Chemokines are a large group of proteins that play a central role in regulating the migration of leukocytes (Tran and Miller, 2003; Rostene et al., 2007). More than 50 chemokines have been shown to be expressed in mammals, and they produce all of their known effects by activating a family of G-protein-coupled receptors. Because of their central role in coordinating inflammatory responses, chemokines and their receptors have been investigated as novel therapeutic targets for anti-inflammatory drug action. Furthermore, the chemokine receptors CXCR4 and CCR5 have been shown to be the cellular receptors mediating HIV-1 infectivity, indicating that chemokine signaling also has a major role to play in HIV-1 pathogenesis.

Approximately a decade ago, reports started to appear in the literature demonstrating that, in addition to the immune system, chemokine signaling may also have important functions in the nervous system (Meucci et al., 1998; Zou et al., 1998). Thus, chemokines and their receptors were found to be expressed by both neurons and glial cells under a variety of conditions. As a result of these observations, investigators have attempted to understand whether there are novel functions for chemokine signaling within the nervous system. Indeed, the evidence now clearly suggests that chemokines represent a unique class of neuromodulators that can regulate phenomena as diverse as development, neuroinflammation, and synaptic transmission. Some of these roles are the result of previously understood biological functions of chemokines (e.g., chemotaxis), whereas others depend on novel nervous system-specific roles. In this Society for Neuroscience mini-symposium, we wanted to present some of the recent data highlighting the emerging view that chemokines act as novel neuromodulators, as well as some of the neuropathological implications of these findings. What follows is a summary of the major themes to be discussed at the symposium, although

Received July 30, 2008; revised Aug. 28, 2008; accepted Aug. 29, 2008.

Correspondence should be addressed to Richard J. Miller, Department of Molecular Pharmacology and Biological Chemistry, Northwestern University Medical School, Chicago, IL 60611. E-mail: r-miller10@northwestern.edu. DOI:10.1523/JNEUROSCI.3588-08.2008

Copyright $\odot 2008$ Society for Neuroscience $\quad$ 0270-6474/08/2811792-04\$15.00/0 it is not a comprehensive review of all of the data available in the literature.

\section{Chemokines, stem cells, and neurogenesis}

Important insights into the biological functions of chemokines can be obtained by just thinking about the evolution of these substances (Huising et al., 2003). It is clear that a rapid expansion of the chemokine family and their receptors accompanied the evolution of a sophisticated immune system. However, the chemokine CXCL12/SDF-1 and its major receptor CXCR4 existed phylogenetically before the development of an immune system. Hence, one would assume that chemokine signaling had some ancient function that was not specifically concerned with the immune system. Indeed, in contrast to many chemokines whose expression is strongly upregulated during inflammatory responses, both CXCL12 and CXCR4 are constitutively expressed at high levels in many tissues, including the developing and adult nervous systems (Banisadr et al., 2002; Stumm et al., 2002; Stumm et al., 2003). Inspection of the phenotypes of CXCL12 and CXCR4 knock-out mice has indicated that the original function of chemokine signaling was to regulate the migration of stem cells (Miller et al., 2008). Indeed, the key role of CXCR4 signaling in maintaining hematopoietic stem cells in the bone marrow stem cell niche is very well established. Antagonists of CXCR4 receptors such as the drug AMD3100 [1,1'-[1,4-phenylenebis(methylene)]bis-1,4,8,11-tetra-azacyclotetradecane octahydrochloride] are used clinically to release hematopoietic stem cells into the circulation for transplantation purposes (Lemoli and D'Addio, 2008). It is also now clear that CXCR4 signaling regulates the migration and development of neural stem cells that form numerous structures in the brain and peripheral nervous systems (Belmadani et al., 2005; Li and Ransohoff, 2008). This is true for the CNS and also for structures such as the dorsal root ganglia (DRG) formed from neural crest progenitors. Interestingly, CXCR4 signaling not only regulates the migration and proliferation of neural stem cells but also regulates the growth of axons once these cells start to develop into neurons (Lieberam et al., 2005; Pujol et al., 2005).

Recent data have demonstrated that CXCR4 signaling continues to play a role in the regulation of adult neurogenesis. It has now been widely demonstrated that new neurons continue to be 
formed throughout adult life in the dentate gyrus (DG) of the hippocampus as well the subventricular zone (SVZ), which functions as a source of new neurons that migrate to the olfactory bulb (Zhao et al., 2008). Both CXCL12 and CXCR4 are expressed in the adult DG and SVZ. In the DG, CXCR4 is expressed by neural stem cells and young granule cells (Tran et al., 2007). Recently Kolodziej et al. (2008) demonstrated that CXCL12 appears to be released in the adult DG and to regulate the development of CXCR4-expressing neural stem cells. These data raise an interesting question: which cells in the DG normally store and release CXCL12 and under what circumstances? This question has been partly answered by Bhattacharyya et al. (2008) who demonstrated that CXCL12 is expressed by neurons in the DG, packaged into neurotransmitter vesicles, and can be released by depolarization like other neurotransmitters. CXCL12 and GABA were observed to be stored in the terminals of interneurons (basket cells) that innervate DG neural stem cells and could cooperate in producing synaptic inputs to these cells. Overall, these data indicate that CXCL12 is actively involved in the neural regulation of DG stem cell development. As we shall discuss below, the idea that chemokines can be expressed by neurons and act as neurotransmitters or neuromodulators suggests a novel role for these substances in the nervous system, which is one focus of the discussions at our symposium. Indeed, it is clear that CXCR4 receptors are normally expressed by a wide variety of neurons throughout the neuraxis and that CXCL12 can influence their activity (Guyon and Nahon, 2007). For example, Apartis and colleagues have shown that CXCL12 can influence the electrical activity of dopaminergic neurons in the substantia nigra, resulting in DA release and changes in locomotor activity (Guyon et al., 2006; Skrzydelski et al., 2007). In addition, activation of CXCR4 expressed by these neurons affords a degree of protection against neurotoxins. Results such as these indicate that neuromodulatory effects of chemokines may influence both the short- and long-term functions of neurons (E. Apartis, unpublished observations).

Neurogenesis in the DG is an ongoing process. However, in other parts of the brain such as the cortex, neurogenesis in adults only occurs at extremely low levels, if at all. However, in response to stroke or other types of brain injury, neural stem cells migrate to areas of brain damage and participate in brain repair (Ohab et al., 2006). Here again it appears that chemokines are important mediators of this process. Neural stem cells express a number of different chemokine receptors, including CXCR4, but also others, such as CCR2, the receptors for the chemokine CCL2/MCP1(Tran et al., 2007). The expression of chemokines such as CXCL12 and CCL2 is upregulated by cells surrounding sites of brain injury and can attract progenitor cells for repair purposes (Belmadani et al., 2006; Liu et al., 2007; Yan et al., 2007). Depending on the situation, chemokine expression can be upregulated by microglia, astrocytes, endothelial cells, and neurons (Ohab et al., 2006; Ohab and Carmichael, 2008). As demonstrated by Banisadr and colleagues, neural and oligodendrocyte progenitors may be targeted to areas of brain repair in association with stroke or multiple sclerosis, and chemokine signaling is important in this migration (G. Banisadr, T. Frederick, C. Freitag, D. Ren, H. Jung, S. D. Miller, R. J. Miller, unpublished observations) (Pluchino et al., 2003). The expression patterns of chemokines synthesized under pathological conditions suggest that they may coordinate brain repair together with angiogenesis and leukocyte influx, giving them a central role in the overall response to injury.

\section{Chemokine/microglial interactions}

The idea that chemokines can act as neuromodulators also appears to be important in communication between neurons and cells of non-neuronal origin in the brain such as microglia, which are important cellular components of the innate immune response in the nervous system. Thus, chemokines may play a central role in coordinating communication between the nervous and immune systems in the context of brain injury and infection. For a long time, neurons have been regarded as targets of activated microglia, exerting little reciprocal control on microglial function. However, it now appears that neurons express "on and off" signals that can inform microglia about their status and so are capable of influencing microglial activity (Biber et al., 2007). One example of this phenomenon is the chemokine CCL21/SLC/ Exodus 2. In contrast to CXCL12 discussed above, which is constitutively expressed at high levels, CCL21 expression is exclusively upregulated in "endangered" neurons in the context of neuropathology (de Haas et al., 2007). Once expressed by these neurons, CCL21 takes on a neuromodulator role as described above for CXCL12. Biber et al. $(2001,2007)$ have shown that, in a middle cerebral artery occlusion mouse model of brain ischemia, cortical neurons rapidly expressed CCL21 in the penumbra of the ischemic core. Similarly, it was demonstrated recently that CCL21 is specifically expressed in neurons in a spinal cord (SC) injury model (Zhao et al., 2007). CCL21 expression was induced in cultured cortical neurons within $2 \mathrm{~h}$ after an excitotoxic insult (Biber et al., 2001; de Jong et al., 2005). It has been proposed that release of CCL21 from damaged neurons activates local microglia and therefore represents a way of informing microglia about neuronal damage. Interestingly, CCL21 does not seem to activate microglia through its cognate receptor CCR7 but via another chemokine receptor, CXCR3 (Biber et al., 2001; Rappert et al., 2002; Rappert et al., 2004). In keeping with its proposed neuromodulator role, it was observed that CCL21 was expressed in neuronal large dense-core vesicles (de Jong et al., 2005, 2008) and that chemokine-filled vesicles could be specifically transported to presynaptic sites in which they can be released (de Jong et al., 2005; Rostene et al., 2007; Jung et al., 2008). Hence, it appears that chemokines can be expressed in neurons under a variety of circumstances and are involved in communication with other neurons and also non-neuronal cells.

\section{Chemokines in the pathogenesis of chronic pain}

The observations summarized above on the CNS have been paralleled by developments on the role of chemokine signaling in the peripheral nervous system. In this case, investigators have been particularly interested in the role of chemokine signaling in different types of chronic pain syndromes such as those resulting from damage to the nervous system or infection with agents such as HIV-1 (McMahon et al., 2005; White et al., 2005a, 2007; Wallace et al., 2007). Generally speaking, it has been observed that chemokine expression in the peripheral nerve and SC is upregulated under these circumstances, and interference with chemokine signaling seems to inhibit hypersensitive pain responses under some circumstances. Two distinct targets for the actions of chemokines have been described, namely nociceptive sensory (DRG) neurons and microglia within the dorsal horn of the SC. One of the best studied examples of this phenomenon is the chemokine CCL2 and its receptor (CCR2). These molecules are not normally expressed in the DRG or SC at very high levels but are strongly upregulated in nociceptive neurons in association with chronic pain states (White et al., 2005b; Sun et al., 2006; Zhang and De Koninck, 2006; Bhangoo et al., 2007). CCR2 acti- 
vation certainly seems to be important in the development of chronic pain because total deletion of CCR2 receptors or CCR2 receptor antagonists block pain behavior in a number of experimental models, whereas overexpression of CCL2 enhances pain hypersensitivity (Abbadie et al., 2003; Bhangoo et al., 2007; Menetski et al., 2007). As with the expression of CXCL12 or CCL21 centrally, expression of CCL2 in DRG neurons is associated with a neuromodulator function. The upregulated chemokine is stored within neurotransmitter vesicles (in this case, together with calcitonin gene-related peptide) and can be released from DRG neurons (Zhang and De Koninck, 2006; Dansereau et al., 2008; Jung et al., 2008). One possible target for CCL2 released in this way are resident spinal microglia, which have been reported to express CCR2 receptors under some circumstances and can then be activated by CCL2 (Abbadie et al., 2003; Zhang et al., 2007). Furthermore, Zhang et al. (2007) have demonstrated that CCL2 can attract circulating macrophages into the SC in which they differentiate into microglia. Thus, upregulated CCL2 may enhance activation of spinal microglia from both central and peripheral sources. In addition to microglial activation, it has also been suggested that CCL2 may act directly on sensory neurons (Oh et al., 2001; White et al., 2005b; Sun et al., 2006). In several pain models, White and colleagues have shown that DRG neurons not only upregulate CCL2 but also CCR2 expression. Activation of CCR2 receptors expressed by these neurons produces excitation, probably primarily via transactivation of TRP channels expressed by the same neurons (Zhang et al., 2005; Dansereau et al., 2008; Jung et al., 2008). CCL2 released centrally may also target CCR2-expressing neurons in the SC (Gosselin et al., 2005).

Release of CCL2 is not the only chemokine-mediated mechanism that is likely to be important in the activation of spinal microglia and establishment of chronic pain. Considerable evidence provided by Milligan and colleagues also suggests a role for the unusual chemokine CX3CL1/fractalkine (Milligan et al., 2004, 2005; Lindia et al., 2005; Clark et al., 2007; Zhuang et al., 2007). CX3CL1, which exists in both membrane-tethered and -soluble states, is the only chemokine in its category and binds to one receptor, CX3CR1. CX3CL1 is expressed by neurons within the SC, whereas its receptors are mostly expressed by microglia. In response to peripheral nerve injury or neuronal excitation in the SC (Verge et al., 2004), matrix metalloproteinases release membrane-tethered fractalkine, and this is accompanied by upregulation of CX3CR1 expression in microglia located in painrelevant laminas of the SC (Lindia et al., 2005). Dorsal horn microglia activated in association with chronic pain increase expression of the lysosomal cysteine protease cathepsin S, an enzyme documented to induce additional fractalkine cleavage (Clark et al., 2007). Inhibition of microglial activation or CX3CL1 action has been shown to reduce pain hypersensitivity in models of neuropathic pain. Hence, both CCL2 and CX3CL1 appear to be involved in reciprocal signaling loops between pain neurons and spinal microglia that mediate the generation of chronic pain behaviors. Other chemokines may also participate in chronic pain under different conditions. Wilson et al. (2008) have observed that pain hypersensitivity resulting from chronic morphine treatment is associated with upregulation of CXCL12 in DRG neurons and that the CXCR4 antagonist AMD3100 can reverse this type of pain. These data strongly indicate that targeting chemokine signaling may represent a novel approach to the treatment of chronic pain syndromes that have proved to be particularly resistant to current forms of therapy.

\section{Conclusions}

Chemokines are very well established as important regulators of the immune system. However, this appears to be only part of the story. As we have discussed above, chemokines and their receptors are expressed in the nervous system under a variety of circumstances in which they play a newly appreciated role as neuromodulators. Chemokine signaling appears to be central in helping to coordinate the response by the nervous system to injury and infection because chemokines can "speak" directly to neurons and also immune cells. We predict that understanding the full range of chemokine functions will provide us with an increased understanding of the mechanisms underlying the progression of different types of diseases of the nervous system, as well as novel therapeutic targets for combating these disorders.

\section{References}

Abbadie C, Lindia JA, Cumiskey AM, Peterson LB, Mudgett JS, Bayne EK, DeMartino JA, MacIntyre DE, Forrest MJ (2003) Impaired neuropathic pain responses in mice lacking the chemokine receptor CCR2. Proc Natl Acad Sci U S A 100:7947-7952.

Banisadr G, Fontanges P, Haour F, Kitabgi P, Rostène W, Mélik ParsadaniantzS (2002) Neuroanatomical distribution of CXCR4 in adult rat brain and its localization in cholinergic and dopaminergic neurons. Eur J Neurosci 16:1661-1671.

Belmadani A, Tran PB, Ren D, Assimacopoulos S, Grove EA, Miller RJ (2005) The chemokine stromal cell-derived factor-1 regulates the migration of sensory neuron progenitors. J Neurosci 25:3995-4003.

Belmadani A, Tran PB, Ren D, Miller RJ (2006) Chemokines regulate the migration of neural progenitors to sites of neuroinflammation. J Neurosci 26:3182-3191.

Bhangoo S, Ren D, Miller RJ, Henry KJ, Lineswala J, Hamdouchi C, Li B, Monahan PE, Chan DM, Ripsch MS, White FA (2007) Delayed functional expression of neuronal chemokine receptors following focal nerve demyelination in the rat: a mechanism for the development of chronic sensitization of peripheral nociceptors. Mol Pain 3:38.

Bhattacharyya BJ, Banisadr G, Jung H, Ren D, Cronshaw DG, Zou Y, Miller RJ (2008) The chemokine stromal cell-derived factor-1 regulates GABAergic inputs to neural progenitors in the postnatal dentate gyrus. J Neurosci 28:6720-6730.

Biber K, Sauter A, Brouwer N, Copray SC, Boddeke HW (2001) Ischemiainduced neuronal expression of the microglia attracting chemokine Secondary Lymphoid-tissue Chemokine (SLC). Glia 34:121-133.

Biber K, Neumann H, Inoue K, Boddeke HW (2007) Neuronal “On” and “Off” signals control microglia. Trends Neurosci 30:596-602.

Clark AK, Yip PK, Grist J, Gentry C, Staniland AA, Marchand F, Dehvari M, Wotherspoon G, Winter J, Ullah J, Bevan S, Malcangio M (2007) Inhibition of spinal microglial cathepsin $S$ for the reversal of neuropathic pain. Proc Natl Acad Sci U S A 104:10655-10660.

Dansereau MA, Gosselin RD, Pohl M, Pommier B, Mechighel P, Mauborgne A, Rostene W, Kitabgi P, Beaudet N, Sarret P, Melik-Parsadaniantz S (2008) Spinal Ccl2 pronociceptive action is no longer effective in Ccr2 receptor antagonist-treated rats. J Neurochem 106:757-769.

de Haas AH, van Weering HR, de Jong EK, Boddeke HW, Biber KP (2007) Neuronal chemokines: versatile messengers in central nervous system cell interaction. Mol Neurobiol 36:137-151.

de Jong EK, Dijkstra IM, Hensens M, Brouwer N, van Amerongen M, Liem RS, Boddeke HW, Biber K (2005) Vesicle-mediated transport and release of CCL21 in endangered neurons: a possible explanation for microglia activation remote from a primary lesion. J Neurosci 25:7548-7557.

de Jong EK, Vinet J, Stanulovic V, Meijer M, Wesseling E, Sjollema K, Boddeke HWGM, Biber K (2008) Expression, transport and axonal sorting of neuronal CCL21 in lare dense core vesicles. FASEB J. Advance online publication. Retrieved Aug. 12, 2008. doi: 10.1096/fj.08-107524.

Gosselin RD, Varela C, Banisadr G, Mechighel P, Rostene W, Kitabgi P, Melik-Parsadaniantz S (2005) Constitutive expression of CCR2 chemokine receptor and inhibition by MCP-1/CCL2 of GABA-induced currents in spinal cord neurones. J Neurochem 95:1023-1034.

Guyon A, Skrzydelsi D, Rovère C, Rostène W, Parsadaniantz SM, Nahon JL (2006) Stromal cell-derived factor-1alpha modulation of the excitability 
of rat substantia nigra dopaminergic neurones: presynaptic mechanisms. J Neurochem 96:1540-1550.

Guyon A, Nahon JL (2007) Multiple actions of the chemokine stromal cellderived factor-1alpha on neuronal activity. J Mol Endocrinol 38:365-376.

Huising MO, Stet RJ, Kruiswijk CP, Savelkoul HF, Lidy Verburg-van Kemenade BM (2003) Molecular evolution of CXC chemokines: extant CXC chemokines originate from the CNS. Trends Immunol 24:307-313.

Jung H, Toth PT, White FA, Miller RJ (2008) Monocyte chemoattractant protein-1 functions as a neuromodulator in dorsal root ganglia neurons. J Neurochem 104:254-263.

Kolodziej A, Schulz S, Guyon A, Wu DF, Pfeiffer M, Odemis V, Höllt V, Stumm R (2008) Tonic activation of CXC chemokine receptor 4 in immature granule cells supports neurogenesis in the adult dentate gyrus. J Neurosci 28:4488-4500.

Lemoli RM, D'Addio A (2008) Hematopoietic stem cell mobilization. Haematologica 93:321-324.

Li M, Ransohoff RM (2008) Multiple roles of chemokine CXCL12 in the central nervous system: a migration from immunology to neurobiology. Prog Neurobiol 84:116-131.

Lieberam I, Agalliu D, Nagasawa T, Ericson J, Jessell TM (2005) A cxcl12CXCR4 chemokine signaling pathway defines the initial trajectory of mammalian motor axons. Neuron 47:667-679.

Lindia JA, McGowan E, Jochnowitz N, Abbadie C (2005) Induction of CX3CL1 expression in astrocytes and CX3CR1 in microglia in the spinal cord of a rat model of neuropathic pain. J Pain 6:434-438.

Liu XS, Zhang ZG, Zhang RL, Gregg SR, Wang L, Yier T, Chopp M (2007) Chemokine ligand 2 (CCL2) induces migration and differentiation of subventricular zone cells after stroke. J Neurosci Res 85:2120-2125.

McMahon SB, Cafferty WB, Marchand F (2005) Immune and glial cell factors as pain mediators and modulators. Exp Neurol 192:444-462.

Menetski J, Mistry S, Lu M, Mudgett JS, Ransohoff RM, Demartino JA, Macintyre DE, Abbadie C (2007) Mice overexpressing chemokine ligand 2 (CCL2) in astrocytes display enhanced nociceptive responses. Neuroscience 149:706-714.

Meucci O, Fatatis A, Simen AA, Bushell TJ, Gray PW, Miller RJ (1998) Chemokines regulate hippocampal neuronal signaling and gp120 neurotoxicity. Proc Natl Acad Sci U S A 95:14500-14505.

Miller RJ, Banisadr G, Bhattacharyya BJ (2008) CXCR4 signaling in the regulation of stem cell migration and development. J Neuroimmunol 198:31-38.

Milligan E, Zapata V, Schoeniger D, Chacur M, Green P, Poole S, Martin D, Maier SF, Watkins LR (2005) An initial investigation of spinal mechanisms underlying pain enhancement induced by fractalkine, a neuronally released chemokine. Eur J Neurosci 22:2775-2782.

Milligan ED, Zapata V, Chacur M, Schoeniger D, Biedenkapp J, O'Connor KA, Verge GM, Chapman G, Green P, Foster AC, Naeve GS, Maier SF, Watkins LR (2004) Evidence that exogenous and endogenous fractalkine can induce spinal nociceptive facilitation in rats. Eur J Neurosci 20:2294-2302.

Oh SB, Tran PB, Gillard SE, Hurley RW, Hammond DL, Miller RJ (2001) Chemokines and glycoprotein 120 produce pain hypersensitivity by directly exciting primary nociceptive neurons. J Neurosci 21:5027-5035.

Ohab JJ, Carmichael ST (2008) Poststroke neurogenesis: emerging principles of migration and localization of immature neurons. Neuroscientist 14:369-380.

Ohab JJ, Fleming S, Blesch A, Carmichael ST (2006) A neurovascular niche for neurogenesis after stroke. J Neurosci 26:13007-13016.

Pluchino S, Quattrini A, Brambilla E, Gritti A, Salani G, Dina G, Galli R, Del Carro U, Amadio S, Bergami A, Furlan R, Comi G, Vescovi AL, Martino G (2003) Injection of adult neurospheres induces recovery in a chronic model of multiple sclerosis. Nature 422:688-694.

Pujol F, Kitabgi P, Boudin H (2005) The chemokine SDF-1 differentially regulates axonal elongation and branching in hippocampal neurons. J Cell Sci 118:1071-1080.

Rappert A, Biber K, Nolte C, Lipp M, Schubel A, Lu B, Gerard NP, Gerard C, Boddeke HW, Kettenmann H (2002) Secondary lymphoid tissue chemokine (CCL21) activates CXCR3 to trigger a $\mathrm{Cl}^{-}$current and chemotaxis in murine microglia. J Immunol 168:3221-3226.

Rappert A, Bechmann I, Pivneva T, Mahlo J, Biber K, Nolte C, Kovac AD, Gerard C, Boddeke HW, Nitsch R, Kettenmann H (2004) CXCR3- dependent microglial recruitment is essential for dendrite loss after brain lesion. J Neurosci 24:8500-8509.

Rostène W, Kitabgi P, Parsadaniantz SM (2007) Chemokines: a new class of neuromodulator? Nat Rev Neurosci 8:895-903.

Skrzydelski D, Guyon A, Daugé V, Rovère C, Apartis E, Kitabgi P, Nahon JL, Rostène W, Parsadaniantz SM (2007) The chemokine stromal cellderived factor-1/CXCL12 activates the nigrostriatal dopamine system. J Neurochem 102:1175-1183.

Stumm RK, Rummel J, Junker V, Culmsee C, Pfeiffer M, Krieglstein J, Höllt V, Schulz S (2002) A dual role for the SDF-1/CXCR4 chemokine receptor system in adult brain: isoform-selective regulation of SDF-1 expression modulates CXCR4-dependent neuronal plasticity and cerebral leukocyte recruitment after focal ischemia. J Neurosci 22:5865-5878.

Stumm RK, Zhou C, Ara T, Lazarini F, Dubois-Dalcq M, Nagasawa T, Höllt V, Schulz S (2003) CXCR4 regulates interneuron migration in the developing neocortex. J Neurosci 23:5123-5130.

Sun JH, Yang B, Donnelly DF, Ma C, LaMotte RH (2006) MCP-1 enhances excitability of nociceptive neurons in chronically compressed dorsal root ganglia. J Neurophysiol 96:2189-2199.

Tran PB, Miller RJ (2003) Chemokine receptors: signposts to brain development and disease. Nat Rev Neurosci 4:444-455.

Tran PB, Banisadr G, Ren D, Chenn A, Miller RJ (2007) Chemokine receptor expression by neural progenitor cells in neurogenic regions of mouse brain. J Comp Neurol 500:1007-1033.

Verge GM, Milligan ED, Maier SF, Watkins LR, Naeve GS, Foster AC (2004) Fractalkine (CX3CL1) and fractalkine receptor (CX3CR1) distribution in spinal cord and dorsal root ganglia under basal and neuropathic pain conditions. Eur J Neurosci 20:1150-1160.

Wallace VC, Blackbeard J, Segerdahl AR, Hasnie F, Pheby T, McMahon SB, Rice AS (2007) Characterization of rodent models of HIV-gp120 and anti-retroviral-associated neuropathic pain. Brain 130:2688-2702.

White FA, Bhangoo SK, Miller RJ (2005a) Chemokines: integrators of pain and inflammation. Nat Rev 4:834-844.

White FA, Sun J, Waters SM, Ma C, Ren D, Ripsch M, Steflik J, Cortright DN, Lamotte RH, Miller RJ (2005b) Excitatory monocyte chemoattractant protein-1 signaling is up-regulated in sensory neurons after chronic compression of the dorsal root ganglion. Proc Natl Acad Sci U S A 102:14092-14097.

White FA, Jung H, Miller RJ (2007) Chemokines and the pathophysiology of neuropathic pain. Proc Natl Acad Sci U S A 104:20151-20158.

Wilson NM, Jung H, Ripsch MS, Miller RJ, White FA (2008) Opioidinduced tactile hypernociception is attenuated by the CXCR4 antagonist, AMD3100. Soc Neurosci Abstr 34:270.14.

Yan YP, Sailor KA, Lang BT, Park SW, Vemuganti R, Dempsey RJ (2007) Monocyte chemoattractant protein-1 plays a critical role in neuroblast migration after focal cerebral ischemia. J Cereb Blood Flow Metab 27:1213-1224.

Zhang J, De Koninck Y (2006) Spatial and temporal relationship between monocyte chemoattractant protein-1 expression and spinal glial activation following peripheral nerve injury. J Neurochem 97:772-783.

Zhang J, Shi XQ, Echeverry S, Mogil JS, De Koninck Y, Rivest S (2007) Expression of CCR2 in both resident and bone marrow-derived microglia plays a critical role in neuropathic pain. J Neurosci 27:12396-12406.

Zhang N, Inan S, Inan S, Cowan A, Sun R, Wang JM, Rogers TJ, Caterina M, Oppenheim JJ (2005) A proinflammatory chemokine, CCL3, sensitizes the heat- and capsaicin-gated ion channel TRPV1. Proc Natl Acad Sci U S A 102:4536-4541.

Zhao C, Deng W, Gage FH (2008) Mechanisms and functional implications of adult neurogenesis. Cell 132:645-660.

Zhao P, Waxman SG, Hains BC (2007) Modulation of thalamic nociceptive processing after spinal cord injury through remote activation of thalamic microglia by cysteine cysteine chemokine ligand 21. J Neurosci 27:8893-8902.

Zhuang ZY, Kawasaki Y, Tan PH, Wen YR, Huang J, Ji RR (2007) Role of the CX3CR1/p38 MAPK pathway in spinal microglia for the development of neuropathic pain following nerve injury-induced cleavage of fractalkine. Brain Behav Immun 21:642-651.

Zou YR, Kottmann AH, Kuroda M, Taniuchi I, Littman DR (1998) Function of the chemokine receptor CXCR4 in haematopoiesis and in cerebellar development. Nature 393:595-599. 